\title{
Informações sobre gestão estratégica de custos divulgadas por companhias abertas brasileiras
}

\author{
Information on Strategic Cost Management Disclosed by Brazilian Companies
}

\section{Franciele Wrubel}

Mestre em Ciências Contábeis pela Universidade do Vale do Rio dos Sinos

Professora Assistente da Universidade Federal do Tocantins (UFT)

Endereço: Quadra 205 Sul, Qi 02, Alameda 10, Lote 11.

CEP: 77015-280 - Palmas/TO - Brasil

E-mail: francielew@uft.edu.br

Telefone: (63) 3232-8097

\section{Carlos Alberto Diehl}

Doutor em Engenharia de Produção pela Universidade Federal de Santa Catarina

Professor Titular do Programa de Pós-Graduação em Ciências Contábeis da Universidade do Vale do Rio dos Sinos (UNISINOS)

Endereço: Av. Unisinos, 950 sala 5A402d - Bairro Cristo Rei

CEP 93022-000 - Porto São Leopoldo /RS - Brasil

E-mail: cd@unisinos.br

Telefone: (51) 3590-8186

\section{Ernani Ott}

Doctor em Ciências Económicas e Empresariales pela Universidade de Deusto (Espanha)

Professor Titular do Programa de Pós-Graduação em Ciências Contábeis da Universidade do Vale do Rio dos Sinos (UNISINOS)

Endereço: Av. Unisinos, 950 sala 5A401d - Bairro Cristo Rei

CEP 93022-000 - Porto São Leopoldo/RS - Brasil

E-mail: ernani@unisinos.br

Telefone: (51) 3590-8186 


\title{
Resumo
}

O presente estudo teve por objetivo identificar e analisar as informações de gestão estratégica de custos (GEC), divulgadas nos relatórios de 2005, 2006 e 2007, das companhias abertas brasileiras listadas nos níveis de governança corporativa (GC) da BOVESPA. Utilizando a técnica análise de conteúdo classificaram-se as informações em 16 categorias, baseadas nos temas-chave de Shank e Govindarajan (1997). A média foi de 212 sentenças por companhia. A quantidade de divulgação está relacionada com o tamanho dos relatórios, mas não com o tamanho das companhias ou nível de GC. A principal diferença entre os três clusters encontrados é a quantidade de informações divulgadas.

Palavras-Chave: Gestão Estratégica de Custos; Evidenciação; Governança Corporativa.

\begin{abstract}
This study aimed to identify and analyze information in strategic cost management (GEC), disclosed in the reports for 2005, 2006 and 2007, of Brazilian companies listed in levels of corporate governance (CG) of BOVESPA. Using content analysis of where classified information in 16 categories, based on key themes of Shank and Govindarajan (1997). The average sentence was 212 per company. The amount of disclosure is related to the size of the reports, but not with the size of companies or level of GC. The main difference between the three clusters found is the amount of information disclosed.
\end{abstract}

Key words: Strategic Cost Management; Disclosure, Corporate Governance.

\section{Introdução}

A informação é cada vez mais um elemento indispensável aos gestores das organizações que atuam em ambiente de negócios dinâmico e altamente competitivo, pautado por constantes modificações e inovações tecnológicas. $\mathrm{Na}$ busca por melhor posição competitiva são necessárias aos gestores, entre outras, informações sobre custos. Na descrição de Lockamy III (2003, p. 1), o "advento da competitividade global acelerada, reduzido ciclos de produtos, rápidos avanços tecnológicos, organizacionais e entre cadeias tem aumentado drasticamente a necessidade de abordagens mais eficazes de gestão dos custos".

Shank e Govindarajan (1997, p. 59) assinalam que "[...] gerenciar custos eficazmente exige um enfoque amplo, externo à empresa [...]". Informações de custos devem ser utilizadas com esse enfoque. Os acontecimentos externos à companhia também podem afetá-la e por isso devem ser considerados durante a gestão dos custos e elaboração das estratégias.

Para atender as demandas mercadológicas e as necessidades de adaptação das organizações a um contexto de busca por melhoria contínua da competitividade, foi proposta a Gestão Estratégica de Custos - GEC que, para Shank e Govindarajan (1997, p. 4) é definida como "uma análise de custos, vista sob um contexto mais amplo, em que os elementos estratégicos tornam-se mais conscientes, explícitos e formais".

As companhias necessitam estar sintonizadas com as peculiaridades do 
ambiente em que atuam, interagindo com seus fornecedores, concorrentes e clientes, a fim de adotar as decisões mais vantajosas. Para isso, Shank e Govindarajan (1997) mencionam algumas práticas de gestão estratégica de custos: custeio baseado em atividades, análise de cadeia de valor, dos custos da qualidade e dos direcionadores de custos. Ou, ainda, Faria e Costa (2005) acrescentam a gestão de custos logísticos; Ellram e Siferd (1993) referem o custo total de propriedade; Monden (1999) menciona o custo-meta, entre outras práticas.

$\mathrm{Na}$ GEC, segundo Anderson (2006), ocorre o alinhamento dos recursos de uma empresa e a estrutura de custos associados com a estratégia de longo prazo e as táticas de curto prazo. Com uma estrutura de custos alinhada com a estratégia e mantendo as atividades de forma consistente, a companhia também poderá, por exemplo, ser atrativa para novos investidores. Para alcançar a vantagem competitiva sustentável é preciso definir o seu posicionamento estratégico por meio da formulação de prioridades estratégicas - diferenciação ou liderança em custos (PORTER, 1989). Para Diehl (2004, p. 25), “é necessário conhecerem-se as relações entre controle de custos e estratégia da organização, de forma a poder analisar quais características são importantes para o alinhamento entre estes".

Uma forma de a companhia buscar informações de outras pertencentes à sua cadeia de valor e transmitir suas informações e resultados aos interessados é mediante a divulgação em relatórios. Essa divulgação (disclosure ou evidenciação) se refere à forma adotada pelos gestores para se comunicarem com os acionistas e com demais interessados, apresentando o desempenho da companhia, perspectivas futuras e outras informações, visando apoiar os investidores e demais stakeholders nas suas decisões. Esse tema tem gerado diversas pesquisas como a de Lanzana (2004), sobre a relação entre o nível de disclosure das empresas brasileiras de capital aberto e a governança corporativa das mesmas. Nossa (2002) realizou uma análise sobre o disclosure ambiental e em 2003 foi realizada pesquisa por Piacentini (2004) sobre a evidenciação de informações de natureza voluntária praticada por companhias abertas brasileiras dos níveis 1 e 2 de Governança Corporativa da Bolsa de Valores de São Paulo (BOVESPA). Backes (2005) também desenvolveu estudo acerca das informações sobre capital intelectual evidenciadas nos relatórios da administração de companhias abertas brasileiras, mediante aplicação de análise de conteúdo. De forma semelhante, Gallon e Beuren (2006) utilizaram a análise de conteúdo para verificar a evidenciação dos itens obrigatórios, não obrigatórios e não recomendados pela legislação nos relatórios da administração das companhias participantes dos níveis de governança da BOVESPA.

Os aspectos mencionados instigam a realização dessa pesquisa, visando responder a seguinte questão: quais são as informações sobre gestão estratégica de custos divulgadas nos relatórios de companhias abertas brasileiras listadas nos níveis de governança corporativa da BOVESPA? Para respondê-la, o objetivo 
geral do estudo é identificar e analisar as informações sobre gestão estratégica de custos divulgadas nos relatórios de companhias abertas brasileiras listadas nos níveis de governança corporativa da BOVESPA.

As companhias utilizam estes relatórios para prestar contas aos investidores e outros interessados como fornecedores, credores e clientes, que são partes interessadas nessas informações para a tomada de decisões, e que buscam aprimorar os relacionamentos com os membros integrantes da cadeia de valor. Embora alguns estudos têm tratado do tema divulgação, como os anteriormente citados, não foram encontradas pesquisas sobre divulgação de informações relacionadas com GEC, mesmo se reconhecendo a sua relevância para a tomada de decisões dos gestores e investidores e para a identificação de perspectivas futuras das companhias.

Este artigo é composto, além dessa introdução, por uma seção sobre o referencial teórico acerca de gestão estratégica de custos, evidenciação e governança, seguida dos procedimentos metodológicos. Após, são apresentados os resultados e as considerações finais, encerrando com as referências.

\section{Referencial Teórico}

\subsection{Gestão estratégica de custos}

A gestão estratégica de custos tem sido muito debatida nos últimos anos, o que gerou pesquisas como as de Cooper e Slagmulder (1999, 2003, 2004), Bacic (1994), Shank e Govindarajan (1997) e Fu (2007); discussões sobre práticas, como o custeio baseado em atividades, em trabalho de Nakagawa (1994), ou conforme Ellram e Siferd (1993), tratando sobre o custo total de propriedade, de Ellram (2006) sobre custo-meta e a de Diehl (1997), que propôs um método de mensuração dos custos intangíveis.

A GEC, para Cooper e Slagmulder (1998, p. 14), é a “aplicação das técnicas de gestão de custos de maneira que, simultaneamente, melhore a posição estratégica de uma empresa e reduza seus custos". Para atender seus propósitos, a GEC se baseia em três temas-chave, conforme abordagem de Shank e Govindarajan (1997, p. 8): “(1) Análise da cadeia de valor; (2) Análise do posicionamento estratégico; (3) Análise dos direcionadores de custos". Cada um deles também vem sendo tema central de estudos sobre organizações, de forma que os custos, nesses casos, são observados sob perspectiva mais ampla e externa do que a utilizada na análise limitada ao ambiente interno das organizações. Na seqüência eles são detalhados.

\subsubsection{Análise da cadeia de valor}


A cadeia de valor torna-se um importante referencial para a tomada de decisões na gestão estratégica, porque envolve acontecimentos externos à empresa que impactam nas suas operações e nos seus custos. Os fornecedores não produzem e entregam apenas insumos que serão utilizados nas atividades de valor de uma empresa, mas influenciam de modo importante os custos e posição de custos/diferenciação da empresa (PORTER, 1989; SHANK; GOVINDARAJAN, 1997). É necessário que essas empresas estendam sua atenção aos clientes e fornecedores, por meio da integração externa, denominada pelos autores de gestão da cadeia de suprimentos.

Um desafio na gestão de custos é motivar os participantes da cadeia de valor a reforçar o seu próprio retorno, de forma a aumentar em vez de diminuir os retornos para toda a cadeia (ANDERSON, 2006). Nesse contexto, a análise do lucro por cliente pode ser uma prática para auxiliar na mensuração e gerenciamento da relação da empresa com o cliente. A análise da cadeia de valor e das ligações da empresa com os seus fornecedores e clientes não é uma perspectiva restrita e, sim, importante para determinar onde, na cadeia do cliente, o valor pode ser aumentado ou os custos reduzidos (SHANK; GOVINDARAJAN, 1997).

Rocha (1999) ressalta que é crescente a tendência a se formarem parcerias entre a companhia e seus principais clientes. Na relação cliente-empresa, o autor explica a importância da interação operacional e acompanhamento das informações dessa relação para uma possível otimização da gestão de custos e resultados. A empresa pode "exportar" suas ineficiências para os clientes, sob a forma de custos embutidos nos preços, assim como é verdade que parte dessas ineficiências pode ter sua origem na maneira sub-ótima com que eles executam certas operações.

Para Porter (1989, p. 33), "toda a empresa é uma reunião de atividades que são executadas para projetar, produzir, comercializar, entregar e sustentar seu produto". O autor entende que essas atividades podem ser representadas fazendo-se uso de uma cadeia de valor. A representação da cadeia de valor de uma organização, para o autor, consiste em margem e atividades de valor. Estas são as atividades físicas e tecnologicamente distintas, empregando insumos adquiridos, recursos humanos e alguma forma de tecnologia. A margem é a diferença entre o valor total e o custo coletivo da execução das atividades de valor.

As "relações entre o modo como uma atividade de valor é executada e o custo ou desempenho de uma outra", é o que Porter (1989, p. 44) nomeia "Elos". Existem os elos horizontais ou internos (cadeia de valor interna) e os elos verticais ou externos (cadeia de valor externa). Os elos existem não só dentro da cadeia de valor de uma empresa, mas também entre a cadeia de uma empresa e as cadeias de valor dos fornecedores e dos canais, de forma que o modo com que as atividades são executadas afetam o custo ou desempenho das atividades de uma empresa (e 
vice-versa) (PORTER, 1989).

A cadeia de valor externa possui diversas etapas (também denominadas de estágios, partes ou ainda atividades estratégicas relevantes). Conforme Shank e Govindarajan (1997), quando uma empresa participa de diversas etapas da cadeia de valor ela é denominada verticalmente integrada. Uma empresa pode comprar componentes em vez de fabricá-los ou contratar uma assistência técnica em vez de organizá-la internamente (PORTER, 1989). Dessa forma, com base nos autores, integração vertical é o grau no qual as diferentes etapas ao longo da cadeia de valor são executadas por uma mesma empresa.

\subsubsection{Análise do posicionamento estratégico}

O segundo tema da Gestão Estratégica de Custos está ligado à análise da estratégia da unidade de negócios e "depende de dois aspectos inter-relacionados: (1) sua missão ou metas, e (2) a forma que a unidade de negócios escolhe para competir em seu segmento para realizar tais metas [...] [sua] vantagem competitiva" (SHANK; GOVINDARAJAN, 1997, p. 117). Os autores mencionam que a missão ou metas dividem-se em: construir, manter e colher.

Quanto à forma escolhida para competir ou alcançar a vantagem competitiva, Porter (1989) entende que, dependendo da estratégia competitiva escolhida pela empresa, que pode ser a liderança em custos ou a diferenciação, essa requer conjuntos diferentes de estrutura organizacional, de controles operacionais e de estilos de gerência. Para Shank e Govindarajan (1997, p. 61-62), "tanto intuitiva quanto teoricamente, a vantagem competitiva no mercado advém em última instância de oferecer mais valor ao cliente por um custo equivalente (isto é, diferenciação) ou valor equivalente por um custo inferior (isto é, baixo custo)". Diferentes estratégias envolvem diferentes posturas na gestão de custos. O posicionamento estratégico merece atenção dos gestores das companhias, pois, segundo Shank e Govindarajan (1997, p. 18-19), "na gestão estratégica de custos, o papel da análise de custos difere de inúmeras formas, dependendo de como a empresa escolha competir". Na GEC a atenção dada ao posicionamento estratégico também precisa ser atribuída ao elemento "Direcionadores de Custos", abordado a seguir, pois além de escolher como competir para analisar custos, a empresa tomará decisões e fará outras escolhas que os determinarão.

\subsubsection{Análise dos direcionadores de custos}

A compreensão do comportamento dos custos de uma determinada área ou situação de negócio, especialmente, no caso de linhas variadas de produtos que servem a distintos segmentos de mercado, necessita o conhecimento das inter- 
relações existentes no conjunto dos geradores de custos. Shank e Govindarajan (1997) propõem os direcionadores de custos para análise de uma empresa com relação às decisões estratégicas e Riley (1987 apud SHANK; GOVINDARAJAN, 1997) menciona que eles podem ser divididos em duas categorias: os estruturais e os de execução. Os direcionadores estruturais determinam em grande parte o comportamento de seus custos (SHANK; GOVINDARAJAN, 1997). Segundo os autores, eles são: Escala: o tamanho do investimento a ser feito em produção, pesquisa e desenvolvimento e em recursos de marketing; Escopo: grau de integração vertical. A integração horizontal é mais relacionada à escala; Experiência: quantas vezes no passado a empresa já fez o que está fazendo agora; Tecnologia: que tecnologias de processos são usadas em cada fase da cadeia de valor da empresa; Complexidade: a amplitude da linha de produtos ou de serviços a ser oferecida aos clientes (SHANK; GOVINDARAJAN, 1997).

Já os direcionadores de execução "são aqueles determinantes da posição de custos de uma empresa que dependem de sua capacidade de executar de forma bem-sucedida" (SHANK; GOVINDARAJAN, 1997, p. 24), e esses são listados: Envolvimento da força de trabalho (participação) - o conceito de comprometimento da força de trabalho com a melhoria contínua; Gestão da qualidade total: crenças e realizações objetivando a qualidade do produto e do processo; Utilização da capacidade: dadas as escolhas de escala na construção da unidade; Eficiência do layout das instalações: o quão eficiente, em comparação com as normas atuais, é o layout; Configuração do produto: se o projeto ou a formulação são eficazes; Exploração de ligações com os fornecedores e/ou clientes para cadeia de valor da empresa.

Os direcionadores de custos também são assim denominados por Hansen e Mowen (2001). Porter (1989) os denomina de "condutores de custos" e outros autores como Rocha (1999), de "determinantes de custos"

\subsection{Evidenciação e governança corporativa}

Para Lanzana (2004), a evidenciação é relevante para a discussão corporativa, já que é uma das formas mais importantes dos gestores das empresas se comunicarem com os seus acionistas, com o mercado em geral e de apresentarem o desempenho da administração. Em um sentido amplo, evidenciação ou disclosure significa o ato de fornecer informações. Na área contábil, para Hendriksen e Van Breda (1999), o disclosure está ligado ao objetivo da contabilidade, referindo-se à divulgação de informações a respeito das atividades de uma entidade por meio de relatórios contábeis.

A comunicação de informações aos interessados "não deve restringir-se ao desempenho econômico-financeiro, mas deve contemplar também os demais 
fatores (inclusive intangíveis) que norteiam a ação empresarial e que conduzem à criação de valor" (IBGC, 2008, p. 6). Pode-se inferir, então, que o disclosure possui um sentido amplo, pois cada empresa deverá divulgar toda e qualquer informação que possa ser útil ao interessado externo e que possa conduzi-lo a uma avaliação coerente da entidade. São diversas as partes interessadas (stakeholders) no disclosure, e também na credibilidade que essa informação possua. Porém, as informações sobre GEC podem ser citadas como exemplo de tipo de informação que se encaixa nos argumentos, como aqueles destacados por Hendriksen e Van Breda (1999), para a não divulgação, pois elas podem ser consideradas estratégicas.

A governança corporativa, conceituada pelo IBGC (2008, p. 6) como "o sistema pelo qual as sociedades são dirigidas e monitoradas, envolvendo os relacionamentos entre Acionistas, Conselho de Administração, Diretoria, Auditoria Independente e Conselho Fiscal", tem como principais finalidades "aumentar o valor da sociedade, facilitar seu acesso ao capital e contribuir para a sua perenidade". Para alcançar os seus objetivos, ela se apóia nos princípios de equidade, prestação responsável de contas (accountability), responsabilidade corporativa e transparência (IBGC, 2008).

O disclosure possui grande importância também para a concretização dos demais princípios da governança, uma vez que se torna impossível aos stakeholders acompanhar a prestação responsável de contas ou obter o tratamento justo e igualitário pretendido com a governança, sem que seja dado aos mesmos meios para conhecerem, da forma mais quantitativa e qualitativa possível, as informações acerca da corporação de seu interesse. Esse conhecimento, via de regra, se dá por meio do disclosure.

A BOVESPA (2008) classifica as organizações de acordo com três níveis de governança corporativa: Novo Mercado, Nível 1 e Nível 2. No Novo Mercado são classificadas as empresas que optam pela adoção de práticas de governança mais rígidas que aquelas presentes na legislação brasileira. Essas regras ampliam os direitos dos acionistas, melhoram a qualidade das informações prestadas pelas companhias e oferecem aos investidores maior segurança jurídica quanto à obediência aos compromissos firmados.

As companhias listadas no Nível 1, segundo a BOVESPA (2008) o mais baixo nível de governança corporativa, comprometem-se, principalmente, com melhorias na prestação de informações ao mercado e com a dispersão acionária. Para a classificação como Companhia Nível 2, além da aceitação das obrigações contidas no Nível 1, a companhia e seus controladores adotam um conjunto mais amplo de práticas de governança e de direitos adicionais para os acionistas minoritários (BOVESPA, 2008). 


\section{Procedimentos metodológicos}

Foram utilizados relatórios divulgados pelas companhias para identificar as informações constantes sobre GEC e, por isso a pesquisa, de acordo com Lakatos e Marconi (1991), é de natureza aplicada, pois objetiva a geração de conhecimentos para a solução de problemas mediante aplicação prática. Quanto à forma de abordagem do problema ela é qualitativa e quantitativa: qualitativa, quando as informações sobre GEC divulgadas são categorizadas; e quantitativa, por se efetuar a quantificação e a análise destas informações mediante o uso de recursos estatísticos. Do ponto de vista dos objetivos a pesquisa é descritiva, pois se descreve as informações sobre GEC encontradas e sua forma de apresentação. A pesquisa classifica-se, segundo os procedimentos técnicos, como pesquisa documental, por ter como fonte de dados publicações oficiais das companhias definidas para o estudo, em seu formato original.

\subsection{Definição das categorias de pesquisa}

Para a definição das categorias de pesquisa foi usado o método Delphi (RIGGS, 1983), mediante a participação de 3 especialistas em GEC pesquisadores na área, atuantes em programas de pós-graduação em Contabilidade, em Engenharia de Produção e em Economia Industrial, todos com nível de Doutorado. Por meio de 3 rodadas Delphi remetidas a eles e respondidas por e-mail, foi obtido consenso acerca das categorias sobre GEC utilizadas neste estudo. Foram definidos 3 temas-chave de pesquisa, a partir do proposto por Shank e Govindarajan (1997) e diversas categorias para cada um, conforme mostrado no Quadro 1.

O ponto de partida para as categorias foram, principalmente, os trabalhos de: Porter (1989); Ellram e Siferd (1993); Nakagawa (1994); Rocha (1995); Diehl (1997); Sakurai (1997); Rocha (1999); Boisvert (1999); Hansen e Mowen (2001); Robles Jr. (2003); Tinoco e Kramer (2004); Bartz, Staudt e Souza (2005); Faria e Costa (2005); Monden (1999); Ball (2006); Ellram (2006); Aguiar e Rocha (2007) e Souza e Rocha (2008).

Quadro 1: Relação de categorias sobre GEC

\begin{tabular}{|c|c|}
\hline \multirow{2}{*}{$\begin{array}{l}\text { Temas-chave/ categorias } \\
\text { Análise da cadeia de valor } \\
\text { - TCO - Custo Total de Propriedade } \\
\text { - Contabilidade Aberta (Open-Book Accounting) } \\
\text { - ABC / ABM (Custeio e Gestão Baseados em Atividades) } \\
\text { - Alianças Estratégicas (Parcerias/Joint Ventures) } \\
\text { - Custos interorganizacionais }\end{array}$} & \\
\hline & $\begin{array}{l}\text { Análise dos direcionadores de custos } \\
\text { - Direcionadores/ Determinantes de Custos } \\
\text { - Custos da Qualidade } \\
\text { Análise do posicionamento estratégico }\end{array}$ \\
\hline $\begin{array}{ll}\text { - Custos interorganizacionais } & \\
\text { - Custos Ambientais } & \text { - Lucro por Cliente } \\
\text { - Custo dos Concorrentes } & \text { - Cadeia de Valor } \\
\text { - Custos Intangíveis } & \text { - Custos Logísticos } \\
\end{array}$ & $\begin{array}{l}\text { - A forma escolhida para competir em seu } \\
\text { segmento (Vantagem competitiva) } \\
\text { - Custo-Meta/Custo-Alvo (Target Cost) } \\
\text { - Missão ou metas }\end{array}$ \\
\hline
\end{tabular}




\subsection{Coleta e tratamento dos dados}

O universo da pesquisa é constituído pelas companhias abertas brasileiras, sendo que se investigaram os relatórios dos anos de 2005, 2006 e 2007 daquelas listadas em 2007 na BOVESPA nos níveis de governança corporativa, totalizando 140 companhias. Essa opção justifica-se pelo fato de que esses relatórios possuem informações oficiais, além do fato de que as companhias pertencentes ao conjunto de normas de conduta definidas pela BOVESPA se comprometem, entre outras práticas, com melhorias na prestação de informações.

Foi retirada desse universo uma pré-amostra, a partir de escolha aleatória de 30 relatórios. Após a categorização das informações sobre GEC nos relatórios escolhidos, foram utilizados os dados da categoria com o maior Coeficiente de Variação de Pearson (CVP) para calcular a amostra definitiva da pesquisa, com 5\%de significância. O maior CVP encontrado foi 5,477 na categoria de Lucro por Cliente; o desvio-padrão dessa categoria foi 0,9129, a média 0,1667 e a margem de erro de 0,5 , que representa $10 \%$ da amplitude dos dados dessa categoria ( 0 a 5 ). O cálculo para a amostra final indicou 13 companhias, sinalizando que a amostra inicial é suficiente, pois excede o mínimo necessário. Os relatórios pesquisados foram visualizados com o auxílio do Sistema de Divulgação Externa ITR/DFP/ IAN, versão 8.2 (Junho/2007), também disponível para download na página da internet da BOVESPA.

Para o tratamento dos dados foi utilizada a técnica de análise de conteúdo, uma vez que a apresentação dos dados nos relatórios é em formato de texto ou mensagem (BARDIN, 1995). O estudo envolveu o tratamento dos dados qualitativos de forma quantitativa, por meio da aplicação de testes estatísticos (análise de clusters e correlação) e análise descritiva, conforme descrito na seqüência.

Os dados coletados foram tabulados, e buscando agrupá-los e identificar companhias com características comuns, foi utilizada a análise de clusters. Para isso, fez-se uso do programa SPSS Statistics 15.0 (Statistical Package for the Social Sciences) e da Análise Hierárquica de Aglomerados ou Análise de Clusters (Hierarchical Cluster Analysis) que, para Malhotra (2006, p. 572), “é uma técnica usada para classificar objetos ou casos em grupos relativamente homogêneos denominados clusters".

Foram analisados 30 relatórios e utilizadas 16 variáveis - cada subcategoria de GEC constituiu uma variável. Algumas disponibilizaram apenas parte dos relatórios voluntários existentes, sendo assim, somente os disponibilizados por elas foram analisados. Os relatórios pertencentes às Controladas ou Coligadas da companhia não foram analisados.

\section{Análise Das Evidências}


As companhias investigadas pertencem a diversos setores de atividade, de acordo com a classificação utilizada pela BOVESPA (2008), sendo que os mais representativos são o da Indústria de Transformação (33,3\%); o setor de Construção de Edifícios (20\%); e o setor de Eletricidade e Gás (6,7\%), que totalizam 60\%, enquanto os demais setores somam $40 \%$. A quantidade total de páginas dos relatórios foi 5.071, com uma média de 169 páginas de relatório por companhia.

\subsection{Apresentação e análise dos resultados}

\subsubsection{Informações sobre gestão estratégica de custos divulgadas nos relatórios}

Os totais de sentenças com informações divulgadas sobre Gestão Estratégica de Custos nos relatórios examinados estão relacionados, em ordem crescente, na Tabela 1. Percebe-se que a companhia que mais divulgou foi a Braskem, com 822 sentenças, e a que menos informou foi a Even, com 48 sentenças.

Tabela 1: Total de sentenças com informações sobre GEC

\begin{tabular}{ll|ll|ll}
\hline Companhia (ano) & QS & Companhia (ano) & QS & Companhia (ano) & QS \\
\hline Even (2006) & 48 & Saraiva (2005) & 113 & EDP Energias (2007) & 238 \\
Fras-le (2005) & 59 & Iochpe maxion (2006) & 126 & Medial Saúde (2007) & 246 \\
Mangels industrial (2005) & 67 & Odontoprev (2007) & 141 & EDP Energias (2005) & 273 \\
Unibanco (2006) & 67 & Porto seguro (2007) & 163 & Copasa MG (2005) & 273 \\
PDG realty (2006) & 72 & Klabin segall(2007) & 165 & Gafisa (2005) & 316 \\
Klabin (2006) & 76 & WEG (2006) & 176 & Randon (2007) & 362 \\
Company (2006) & 89 & Banco Pine (2006) & 178 & Minerva (2007) & 409 \\
Cia Providência (2007) & 104 & Brasilagro (2005) & 191 & Gol (2005) & 468 \\
Eletropaulo (2005) & 110 & Brasil Ecodiesel (2005) & 201 & ALL (2007) & 485 \\
Brascan (2006) & 111 & Medial Saúde (2006) & 225 & Braskem (2005) & 822 \\
\hline
\end{tabular}

Fonte: Dados da Pesquisa

A dispersão da correlação entre o tamanho do relatório das companhias e as informações sobre Gestão Estratégica de Custos pode ser observada no Gráfico 1. A companhia Braskem possui um relatório de 443 páginas e um total de 822 sentenças com informações sobre GEC divulgadas (443, 822), representando, assim, o ponto mais distante na dispersão, conforme destacado. Essa companhia possui o maior relatório e a maior divulgação de todas as companhias da amostra. Há uma correlação de $77,7 \%$ entre o tamanho do relatório e o número de informações divulgadas. Entretanto, não existe correlação entre o número de informações divulgadas e o tamanho das companhias (medido pelo valor total do ativo). Utilizou-se o critério considerado na Lei $\mathrm{N}^{\mathrm{o}}$ 11.638/07 para a classificação de empresas de grande porte, tendo-se nesta pesquisa $86,7 \%$ de companhias com essa classificação, ou seja, que apresentavam um ativo total maior do que R $\$ 240$ milhões no final do exercício coincidente com o relatório examinado. 
Gráfico 1: Correlação entre tamanho do relatório e divulgação de informações sobre GEC

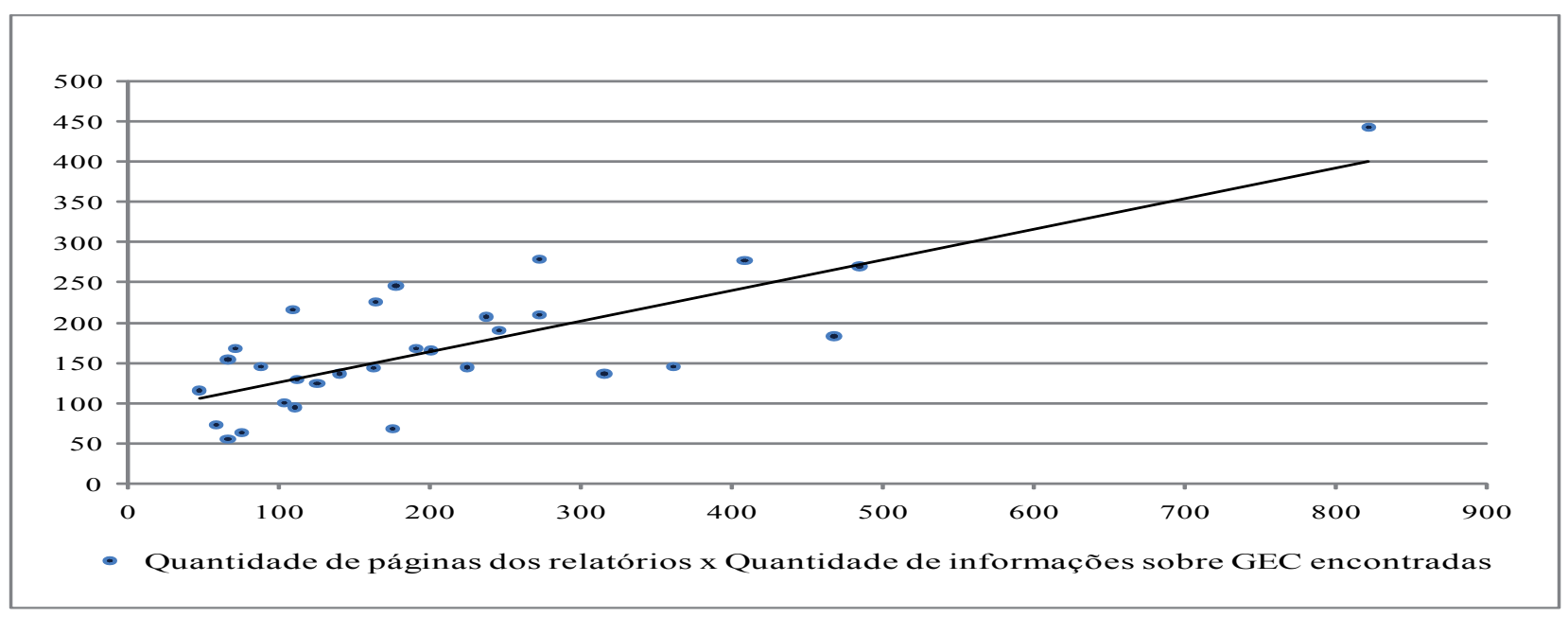

Fonte: Dados da Pesquisa

\subsubsection{Análise dos temas de gestão estratégica de custos}

$\mathrm{Na}$ análise dos relatórios divulgados pelas companhias contendo informações sobre GEC, 47,2\% focalizavam a Análise da Cadeia de Valor; 49,6\% a Análise dos Direcionadores de Custos; e 3,2 \% o Posicionamento Estratégico. Cada um dos três temas teve suas informações classificadas em 16 categorias específicas. As categorias $\mathrm{ABC} / \mathrm{ABM}$, amplamente discutidas por pesquisadores, e Open-Book Accounting ou Contabilidade aberta, prática que recentemente vem merecendo maiores discussões de pesquisadores como Aguiar e Rocha (2007), não foram mencionadas pelas companhias pesquisadas, ou seja, apenas 14 das 16 categorias foram citadas no total. $O$ fato de não se encontrar informações sobre $\mathrm{ABC} / \mathrm{ABM}$ vai ao encontro de outras pesquisas realizadas no Brasil (BEUREN; ROEDEL, 2002; SOUZA; LISBOA; ROCHA, 2004). Inclusive, autores como Diehl (2004) alegam que o uso do $\mathrm{ABC}$ pode ser contrário à estratégia em alguns casos, o que reforça os achados desta pesquisa.

A importância dada pelas companhias para cada categoria de GEC pode variar conforme seu setor de atividade, pois a gestão de alguns custos em especial pode ser prioridade para algumas, enquanto para outras companhias pode ter menor relevância. No total, as companhias mencionam informações sobre GEC 6.374 vezes, com média de 212 por categoria. Algumas das informações encontradas aparecem repetidas entre os relatórios ou em um mesmo relatório e também foram consideradas.

As principais escolhas feitas pelos gestores em relação às atividades estruturais e de execução estão relacionadas à tecnologia que a companhia utiliza, à configuração dos produtos ou serviços oferecidos, à capacidade utilizada, a escala 
e escopo, entre outras, que irão determinar ou direcionar seus custos. Por isso, as informações sobre determinantes ou direcionadores de custos envolvem conteúdo abrangente. Dessa forma, analisando os resultados encontrados, onde a categoria sobre gestão estratégica de custos mais lembrada foi a de Direcionadores de Custos, é possível inferir que as informações mais divulgadas pelas companhias tratam das escolhas realizadas por seus tomadores de decisões em relação aos seus determinantes. A freqüência completa das informações, posicionadas nas categorias de GEC a que pertencem estão apresentadas na Tabela 2. Cada uma das categorias ali apresentadas é objeto de detalhamento nas seções seguintes, sendo estas divididas por tema de gestão estratégica de custos, iniciando com a seção sobre a Análise da Cadeia de Valor.

Tabela 2: Resumo do resultado das categorias de gestão estratégica de custos

\begin{tabular}{|c|c|c|c|c|c|}
\hline \multicolumn{6}{|c|}{ CATEGORIAS DE GESTÃO ESTRATÉGICA DE CUSTOS } \\
\hline TEMA & CATEGORIA & Total & Média & $\%$ & Posição \\
\hline \multirow{9}{*}{$\begin{array}{l}\text { Análise da cadeia de } \\
\text { valor }\end{array}$} & Cadeia de Valor & 1.109 & 36 & 17,40 & 2 \\
\hline & Custos Intangíveis & 673 & 22 & 10,56 & 3 \\
\hline & Custos Ambientais & 508 & 16 & 7,97 & 5 \\
\hline & Custos Logísticos & 349 & 11 & 5,48 & 6 \\
\hline & Alianças Estratégicas & 185 & 6 & 2,90 & 7 \\
\hline & Análise dos Custos dos Concorrentes & 159 & 5 & 2,49 & 9 \\
\hline & TCO (Total Cost of Ownership) & 18 & 0,60 & 0,28 & 11 \\
\hline & Lucro por cliente & 5 & 0,17 & 0,08 & 13 \\
\hline & Gestão de Custos Interorganizacionais & 2 & 0,07 & 0,03 & 14 \\
\hline Análise dos & Direcionadores de Custos & 2.631 & 87 & 41,28 & 1 \\
\hline direcionadores de custos & Custos da Qualidade & 530 & 17 & 8,32 & 4 \\
\hline Análise do & Missão ou Metas & 166 & 5 & 2,60 & 8 \\
\hline posicionamento & A forma escolhida para competir & 32 & 1 & 0,50 & 10 \\
\hline estratégico & Custo-Meta & 7 & 0,23 & 0,11 & 12 \\
\hline Geral & & 6.374 & 212 & 100 & \\
\hline
\end{tabular}

Fonte: Dados da Pesquisa

\subsubsection{Análise da cadeia de valor}

A categoria Cadeia de Valor foi a segunda mais citada, considerando a divulgação de todas as companhias. Conforme mostrado na Tabela 2, a média de citações foi igual a 36 sentenças, sendo que a companhia que mais tratou do assunto o fez 187 vezes, e 36,7\% das companhias apresentaram quantidades de citações acima da média. A divulgação de informações sobre essa categoria ocorre em todas as companhias da amostra. As companhias preocupadas com esse tipo de informação relatavam a identificação da cadeia de valor da qual pertenciam, informações sobre seus principais clientes e fornecedores, além de outros detalhes sobre estes e, também, relatavam sobre contratos de fornecimento de produtos ou serviços.

Sobre as informações da cadeia de valor, segundo Rocha (1999), pode-se 
reconhecer o fato de que o bom desempenho dos fornecedores é importante também para o sucesso da empresa compradora. As informações sobre fornecedores ajudam os administradores na identificação de oportunidades de otimização, formulação e implementação de melhorias.

Cerca de $73 \%$ das companhias pesquisadas mencionaram alguma informação sobre Alianças Estratégicas (Parcerias/Joint Ventures) e destas 54\% com quantidade de sentenças acima ou igual à média da categoria que é igual a 6 . Essa categoria representa 2,9\% do total de informações sobre Gestão Estratégica de Custos. Percebe-se que a maioria das companhias já realizou alguma parceria ou aliança e mencionou em seus relatórios sobre o objetivo, resultado ou benefício desta para os seus negócios.

Além das parcerias ou alianças, quando as companhias identificam e promovem ações conjuntas com seus fornecedores e clientes visando reduzir os custos que não conseguiriam realizar individualmente, ocorre a gestão de Custos Interorganizacionais (AGUIAR; ROCHA, 2007). Sobre isso se observou baixa citação, tornando-se a categoria menos citada. As informações divulgadas referemse à companhia Braskem e aparecem em 2 sentenças.

Foram encontradas informações sobre as cadeias de valor às quais as companhias pertencem, escopo, produtos e contratos de fornecimento. Entretanto, há poucas informações sobre ações coordenadas ou compartilhadas entre as partes da cadeia para gerir custos.

Sobre Custos Ambientais a média de informações foi 16, atingindo 508 sentenças no total das companhias. A maioria das informações encontradas envolvia custos para atender a legislação ambiental ou prevenção. Entretanto, algumas informações sobre o ciclo de vida do produto também foram encontradas. As companhias com maior quantidade de informações divulgadas sobre essa categoria possuem atividades que utilizam basicamente recursos naturais em seus processos de produção: Braskem, Copasa (MG), EDP Energias e Klabin.

Foram identificadas 673 sentenças tratando sobre Custos Intangíveis, ou seja, informações relacionadas a fatores intangíveis e gastos da companhia, sendo que a média por companhia foi de 22 sentenças citadas, representando 10,6\% de todas as informações sobre Gestão Estratégica de Custos. Esse percentual é maior do que o da categoria sobre Custos Ambientais, que representa cerca de $8 \%$ do total.

Identificou-se que a categoria TCO (Total Cost of Ownership) ou Custo Total de Propriedade foi preocupação de 5 companhias, representando $0,3 \%$ do total, conforme Tabela 2. As companhias Brascan, Even, Klabin Segall e Gafisa, do setor de construção e incorporação, e a Brasilagro, do setor agrícola/pecuária, mencionaram sobre a análise realizada antes da aquisição de terreno.

Informações sobre os Custos dos Concorrentes foram mencionadas 159 
vezes no total, sendo que a média foi de apenas 5 vezes, pois 50\% das companhias não mencionaram informações sobre esse assunto. Observa-se que 58\% das informações ficaram distribuídas entre duas companhias: Braskem e Gol. Também se percebe que são vagas as informações divulgadas por todas as companhias. Entre as principais informações reveladas, a companhia Gol comenta sobre a capacidade e rotas das concorrentes e sobre o transporte rodoviário, sendo que a companhia Braskem apresenta informações sobre a capacidade de produção das empresas concorrentes, assim como sobre as características dos produtos fabricados por elas.

Os baixos percentuais de divulgação desse tipo de informação confirmam o abordado por Rocha (1999). O autor cita que a obtenção de dados e informações relevantes sobre clientes, fornecedores e, principalmente, sobre concorrentes, é um processo árduo, pois eles procuram garantir sigilo, embora parcerias com clientes e fornecedores impliquem na necessidade de disclosure.

Sobre os custos dos concorrentes, Casella (2008) explorou em sua pesquisa a possibilidade de utilizar as Demonstrações Contábeis de quatro empresas brasileiras do setor de Celulose e Papel e concluiu que é possível inferir sobre os custos dos concorrentes por meio dessas demonstrações. O autor utilizou as informações constantes nas Demonstrações Contábeis para calcular ou identificar os custos dos concorrentes, enquanto nessa pesquisa observou-se as informações divulgadas pelas companhias sobre a prática dessa análise por elas. Foram encontradas poucas sentenças sobre Análise dos Custos dos Concorrentes, sendo essas com conteúdos vagos.

A categoria Lucro por Cliente revelou ser a preocupação de apenas uma companhia pesquisada, que faz isso em 5 sentenças sobre seus cinco maiores clientes.

Já os Custos Logísticos foram mencionados por 19 companhias, total de 349 sentenças, significando uma média de 11 sentenças por companhia, sendo que isso representa 5,6\% do total de informações divulgadas em todas as categorias. Essa categoria é composta por informações sobre localização de centros de distribuição e custos de distribuição, custos e vantagens de diferentes formas de transportes, custos com infraestrutura de transporte deficitária. As informações sobre gestão de custos logísticos são divulgadas em maior quantidade nas companhias com atuação em todo o território nacional e exportadoras, sendo que, ou suas atividades envolvem o transporte como objeto ou a distribuição dos seus produtos depende de atividades logísticas, como um centro de distribuição, por exemplo.

\subsubsection{Análise dos direcionadores de custos}


A categoria Direcionadores de Custos foi a mais citada (41,3\% do total) e possui média de 87 sentenças por companhia, de acordo com os dados apresentados na Tabela 2. Além disso, foi a categoria mais citada por 28 companhias, com exceção das companhias ALL e Eletropaulo, que mais citaram a categoria Cadeia de Valor. As principais informações divulgadas se referiam à capacidade instalada e utilização da capacidade, configuração do produto, complexidade e tecnologia utilizada. Foram divulgadas algumas informações sobre custos de transação, subcategoria de Direcionadores de Custos. Cita-se o caso da Medial Saúde, que possui custos com a negociação e análise de propostas de planos de saúde.

Ainda, foi possível identificar informações sobre integração vertical e desverticalização. Algumas companhias informaram serem integradas verticalmente e, a sentença com essa indicação foi pontuada na categoria Direcionadores de Custos, por se tratar do escopo de negócio escolhido pela companhia. Informações mencionadas sobre as empresas participantes da integração foram pontuadas na categoria Cadeia de Valor, por tratar sobre elos integrados à companhia.

Custos da Qualidade foram mencionados 530 vezes, uma média de 17 sentenças por categoria (8,3\% do total), sendo que 30\% das companhias citaram quantidade acima da média. As informações divulgadas para essa categoria foram sobre os custos da qualidade de seus produtos ou prestação de serviços, certificado de qualidade e padronização da ISO (Internacional Organization for Standardization) e sobre pesquisas de satisfação dos clientes.

\subsubsection{Análise do posicionamento estratégico}

Nesse tema a categoria Missão ou Metas foi a mais divulgada pelas companhias, 166 vezes, representando $2,6 \%$ do total de todas as categorias, média de 5 sentenças por companhia tratando, principalmente, sobre objetivos de crescimento e ampliação de mercado.

A forma escolhida para competir (vantagem competitiva) teve 32 sentenças, distribuídas em 10 companhias. A companhia responsável por 32\% das informações divulgadas sobre vantagem competitiva foi a GOL, que destacou sua estratégia de baixos custos no período analisado. Algumas companhias mencionaram sobre os públicos-alvo dos seus produtos e serviços, entretanto, não foi possível identificar claramente a existência ou não de companhias que pudessem competir tanto com diferenciação como com baixo custo.

Duas companhias informaram sobre Custo-Meta/Custo-Alvo (Target Costing): Gafisa e ALL. O total foi de 7 sentenças, representando um percentual de apenas $0,11 \%$. O baixo percentual de informações sobre esse tópico, assim como o baixo percentual de informações sobre a forma que a empresa escolhe para competir, comparando com a quantidade de sentenças da categoria mais citada 
nesse tema, Missão ou Metas, permite inferir que as companhias, de modo geral, revelam suas perspectivas quanto ao mercado. Porém, divulgam pouco sobre suas estratégias de competição ou lucro desejável.

\subsubsection{Análise da GEC por nível de governança corporativa}

As informações dos três temas de gestão estratégica de custos também foram analisadas por nível de governança corporativa ao qual cada companhia da amostra pertence, considerando os três níveis da BOVESPA. O nível 1 apresentou 220, o Nível 2, 294 e o Novo Mercado, 191. O teste estatístico de hipóteses, ao nível de 5\% de significância, rejeitou a hipótese H0, ou seja, de que as médias eram diferentes (H0: $\sigma 12 \neq \sigma 22$ ). Com o resultado apresentado não é possível afirmar que quanto maior o nível de governança corporativa mais informações sobre GEC são divulgadas. Isso contradiz a expectativa inicial, uma vez que são esperados, por definição, graus diferentes de divulgação por nível de governança. Para buscar mais subsídios que auxiliassem a explicar o comportamento identificado, foi realizada uma análise de clusters, a seguir detalhada.

\subsection{Análise dos clusters de gestão estratégica de custos}

O procedimento de aglomeração utilizado foi o hierárquico e o método foi o aglomerativo por meio de encadeamento médio. De acordo com Malhotra (2006), a aglomeração hierárquica é um procedimento caracterizado pelo desenvolvimento de uma hierarquia ou estrutura em forma de árvore.

Por meio de dendograma, foram encontrados dois clusters relevantes e formados na mesma escala de significância; o primeiro composto por $18 \mathrm{com}$ panhias, sendo elas: Unibanco, Fras-le, Even Construtura, Mangels, Company, Klabin, Iochpe Maxion, PDG Realty, Cia Providência, Eletropaulo, Brasil Ecodiesel, Weg, Banco Pine, Brascan Residential, Odontoprev, Saraiva, Klabin Segall e Porto Seguro.

O segundo cluster possui 4 companhias: Medial Saúde, EDP Energias, Gafisa e Copasa (MG). As companhias Medial Saúde e EDP Energias participaram da amostra com dois relatórios cada, representando anos diferentes; portanto, as informações não se repetem e as companhias não receberam tratamento ou análise diferenciada das demais. Na análise de clusters esses relatórios classificam-se no Cluster 2. Em escala significante, as companhias ALL e Braskem não pertencem a nenhum dos clusters.

Tanto no Cluster 1 como no Cluster 2 a categoria mais citada foi Direcionadores de Custos, assim como o foi para as companhias de modo geral. As características principais de cada Cluster estão mostradas na Tabela 3. As infor- 
mações mais mencionadas pelas companhias de ambos os clusters pertencem às categorias Cadeia de Valor e Determinantes de Custos. Os percentuais observados nessa tabela também significam que a distribuição de importância dada para as diversas categorias é semelhante para ambos e para as categorias mais citadas.

Tabela 3: Comparativo das informações sobre GEC por cluster

\begin{tabular}{|c|c|c|c|c|c|c|c|c|}
\hline \multicolumn{9}{|c|}{ COMPARATIVO DAS INFORMAÇÕES SOBRE GEC POR CLUSTER } \\
\hline \multirow{3}{*}{$\begin{array}{l}\text { Posiçãa o } \\
1^{\circ}\end{array}$} & \multirow[b]{2}{*}{ Categoria } & \multicolumn{2}{|c|}{ CLUSTER 1} & \multirow[b]{2}{*}{ Acumulado } & \multicolumn{4}{|c|}{ CLUSTER 2} \\
\hline & & Média & Frequência & & Pos. & Méd. & Freq. & Acum. \\
\hline & Direcionadores de Custos & 46 & $40,03 \%$ & $40,03 \%$ & $1^{\circ}$ & 107 & $40,74 \%$ & $40,74 \%$ \\
\hline $2^{\circ}$ & Cadeia de Valor & 19 & $16,17 \%$ & $56,20 \%$ & $3^{\circ}$ & 41 & $15,72 \%$ & $56,46 \%$ \\
\hline $3^{\circ}$ & Custos Intangíveis & 17 & $14,76 \%$ & $70,96 \%$ & $4^{\circ}$ & 29 & $10,88 \%$ & $67,34 \%$ \\
\hline $4^{\circ}$ & Custos Ambientais & 12 & $10,70 \%$ & $81,66 \%$ & $5^{\circ}$ & 22 & $8,53 \%$ & $75,87 \%$ \\
\hline $5^{\circ}$ & Custos Qualidade & 7 & $5,90 \%$ & $87,56 \%$ & $2^{\circ}$ & 44 & $16,68 \%$ & $92,55 \%$ \\
\hline
\end{tabular}

Fonte: Dados da Pesquisa

O que se destaca no Gráfico 2 é que a média de informações para as categorias das companhias do Cluster 2 são maiores, com exceção da categoria de custos logísticos. O fator que influencia para se encontrar maior quantidade divulgada de informações sobre custos logísticos é a companhia possuir atividades logísticas relevantes dentro da cadeia de valor e necessitar de grandes investimentos nessa área. Isso aconteceu para as companhias do Cluster $1 \mathrm{em}$ maior quantidade do que para as do Cluster 2. As companhias que mais detalham sobre sua cadeia de valor também detalham mais sobre seus custos logísticos, com correlação de $24,6 \%$ para as companhias do Cluster 1 e $15,1 \%$ para as do Cluster 2. Para o Cluster 1, 60\% das companhias revelam informações abaixo da média geral. Já as companhias que representam $20 \%$ do total da amostra (Cluster 2), além de divulgar maior quantidade de informações, destacam-se por divulgar mais sobre a gestão de custos da qualidade.

Gráfico 2: Média de informações divulgadas sobre GEC por Cluster

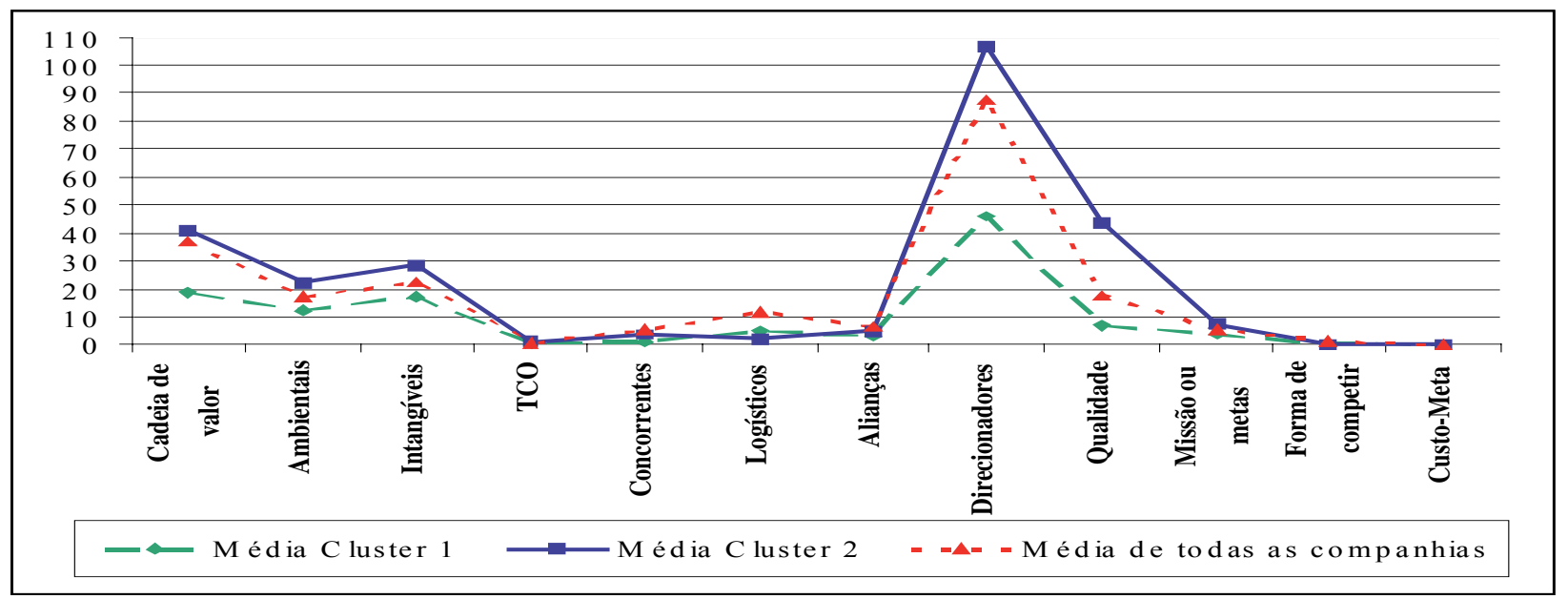


Examinando a Análise dos Direcionadores de Custos, constata-se que $51 \%$ das informações representam direcionadores de custos estruturais para as companhias do Cluster 1, e 31\% para as do Cluster 2. Com isso, observa-se que as companhias do Cluster 2 possuem uma visão de longo prazo mais presente. Isso corrobora o fato de o Cluster 1 divulgar mais informações sobre Custos da Qualidade, categoria que trata sobre um direcionador de custos de execução.

\section{Consideranções Finais}

A prática da gestão estratégica de custos auxilia as companhias a orientarem suas estratégias e assegurarem a sua continuidade. Uma forma de verificar se essas práticas são importantes para as companhias é observar os relatórios que estas elaboram e divulgam. Ao divulgar informações sobre esse tema, a companhia estará demonstrando a preocupação dos seus gestores com essa área e também disponibilizará aos interessados maior suporte para tomar decisões.

A análise da cadeia de valor, dos direcionadores de custos e do posicionamento estratégico são, segundo Shank e Govindarajan (1997), os três temas-chave da Gestão Estratégica de Custos. Estes foram objeto de análise nos relatórios anuais de 2005, 2006 e 2007 das companhias da amostra, tendo-se observado que estas divulgam informações sobre GEC, situando-se a média geral de divulgação em 212 sentenças por companhia. As informações mais citadas tratam sobre direcionadores de custos, cadeia de valor, custos intangíveis, custos ambientais e gestão dos custos da qualidade, representando $85,5 \%$ do total.

Os relatórios revelam as escolhas realizadas pelos gestores, relacionadas aos direcionadores de custos, havendo a identificação da cadeia de valor da qual fazem parte, mostrando assim sua solidez e integração por meio do detalhamento realizado sobre as relações com os clientes e fornecedores das companhias.

Sobre custos intangíveis há a preocupação das companhias em tratar dos gastos com programas sociais, desenvolvimento de recursos humanos e com marca ou patente. Sobre custos ambientais e gestão dos custos da qualidade, conclui-se que os tipos de atividades exercidas pelas companhias influenciam para que as mesmas divulguem mais sobre essas categorias. Isso também ocorre em relação aos custos logísticos, e está relacionado com as atividades de transporte, quando objeto da companhia ou com a dependência de atividades logísticas para a distribuição dos produtos.

As informações sobre GEC ficaram distribuídas nos três temas: Análise dos direcionadores de custos, com 49,6\% do total de informações; Análise da cadeia de valor com 47,2\%; e do posicionamento estratégico com apenas $3,2 \%$, concluindo-se que a maioria das companhias revela poucas informações sobre suas estratégias de competição. Por tratar-se de estratégia, pode ser que os di- 
retores realmente não desejam divulgá-las ou até mesmo por elas não estarem perfeitamente definidas pela companhia. Por meio da análise dos relatórios não foi possível identificar claramente qual a forma escolhida pelas companhias para competir: se por diferenciação ou baixo custo, ou se as mesmas competem tanto com diferenciação como com baixo custo.

O tamanho das companhias, representado pelo valor total do ativo, não possui relação com as informações sobre GEC das quais as mesmas se preocupam. O resultado econômico e financeiro, que representa o lucro líquido, também não explica a preocupação. Já, o tamanho dos relatórios, em função do número de páginas, está relacionado com o total de informações divulgadas, de forma que os maiores relatórios também apresentam mais informações sobre GEC, o que é, de certa forma, tautológico.

A relação das informações divulgadas com o nível de governança corporativa da BOVESPA também foi analisada, e conclui-se que pertencer ao maior nível não significa revelar mais informações sobre GEC. Não foram encontradas diferenças na média de informações entre os níveis 1, 2 e Novo Mercado, ao nível de 5\% de significância. Com isso, observa-se que os níveis de Governança Corporativa aos quais as companhias pertencem não explicam as suas divulgações.

Identificaram-se 2 clusters, sendo um deles composto por companhias que representam $60 \%$ do total da amostra e o outro por $20 \%$ - o restante não foi possível agrupar. Ambos concentram informações sobre direcionadores de custos, cadeia de valor, custos intangíveis, custos ambientais e custos da qualidade. A principal diferença entre eles é que as companhias do Cluster 2 divulgam, em média, maior número de informações que as do Cluster 1 . Cerca de $20 \%$ das companhias (Cluster 2) possuem maior visão de longo prazo quanto aos seus direcionadores de custos, por preocuparem-se mais com os direcionadores estruturais. De maneira comparativa, $60 \%$ das companhias (Cluster 1 ) possuem maior visão de curto prazo e divulgam mais sobre custos da qualidade, um direcionador de execução.

\section{Referências}

AGUIAR, A. B; ROCHA, W. Uma análise da complementaridade entre gestão interorganiza-cional de custos e open-book accounting. 7. Congresso USP de Controladoria e Contabili-dade. São Paulo, 2007.

ANDERSON, S. W. Managing costs and cost structure throughout the value chain: research on strategic cost management. In Chapman, C.; Hopwood, A.; Shields, M. (editor) Handbook of Management Accounting Research. Vol 2. Oxford: Elsevier, 2006. Disponível em: http://ssrn.com/abstract=869070. Acesso em: 17 
de março de 2008.

BACIC, M. J. Escopo da gestão estratégica de custos em face das noções de competitividade e de estratégia empresarial. Congresso Brasileiro de Gestão Estratégica de Custos. 1. São Leopoldo, Unisinos, 1994.

BACKES, R. G. Evidenciação do capital intelectual: análise de conteúdo dos relatórios de administração de companhias abertas brasileiras. Dissertação (Mestrado em Ciências Contá-beis) - UNISINOS, São Leopoldo, 2005.

BALL, S. Making the cost of quality practical. Strategic Finance. Jul./2006. p. 34-41.

BARDIN, L. Análise de conteúdo. Lisboa: Edições 70, 1995.

BARTZ, D; STAUDT, T; SOUZA, M. A. Gestão estratégica de custos: uso da engenharia reversa na análise dos custos de concorrentes. BASE, Set/Dez., 2005. p. $167-175$.

BEUREN, I. M; ROEDEL, A. O uso do custeio baseado em atividades - ABC (Activity Base-ad Costing) nas maiores empresas de Santa Catarina. Revista Contabilidade \& Finanças - USP. São Paulo: Set./Dez., 2002, n. 30, p. 7-18.

BOISVERT, H. Contabilidade por atividades: contabilidade de gestão: práticas avançadas.. São Paulo: Atlas, 1999.

BOVESPA. Bolsa de Valores de São Paulo. Níveis de governança corporativa. Disponível em: http://www.bovespa.com.br. Acesso em: 01 de maio de 2008.

CASELLA, B. M. B. X. Análise de custos de concorrentes - estudo exploratório no setor de celulose e papel. Dissertação (Mestrado em Ciências Contábeis) Programa de Pós-Graduação em Ciências Contábeis, Universidade de São Paulo, São Paulo, 2008.

COOPER, R; SLAGMULDER, R. Cost analysis outside the organization. Cost Manage-ment. Vol. 18, Iss. 3. Boston: May/Jun., 2004.

; . Strategic cost management: expanding scope and boundairies. Cost Management. Vol. 17, Iss. 1. Boston: Jan/Fev, 2003. . Suplly chain management for lean enterprise: interorganizational cost management. Strategic Finance. Vol. 80. Iss. 10. Apr/1999. p. 15-16. . The scope of strategic cost management. Management 
Accounting. Vol. 79. Iss. 8. Feb/1998. ABI/INFORM Global. p. 16-18.

DIEHL, C.A. Proposta de um sistema de avaliação de custos intangíveis. Dissertação (Mestrado em Engenharia de Produção) - UFRGS, Porto Alegre, 1997.

. Controle estratégico de custos: um modelo referencial avançado. Tese (Doutora-do em Engenharia da Produção) - Programa de Pós Graduação em Engenharia da Produção. Universidade Federal de Santa Catarina, Florianópolis, 2004.

EL-KELETY, I. A. E. M. A. E. Towards a conceptual framework for strategic cost man-agement: the concept, objective, and instruments. $556 \mathrm{f}$. Dissertação. Chemnitz University of Technology, Chemnitz, 2006. Disponível em: http://archiv. tu-chemnitz.de/pub/2006/0115/index.html. Acesso em: 21 de maio de 2008

ELLRAM, L. M. The implementation of target costing in the United States: theory versus practice. Journal of Supply Chain Managemet. Vol. 42. 2006. p. 13-26.

ELLRAM, L. M. SIFERD, S. P. Purchasing: the cornestone of the total cost of ownership. Journal of Business Logistics. Vol. 14. 1993. p. 163-185.

FARIA, A. C; COSTA, M. F. G. Gestão de custos logísticos: custeio baseado em atividades (ABC); balanced scorecard (BSC); valor econômico agregado (EVA). São Paulo: Atlas, 2005.

FU, Y. Strategic cost management in e-supply chain. Asian-Pacific Management Account-ing Journal. Vol. 2. Issue, 1, 2007. p. 89-119.

GALLON, A. V; BEUREN, I. M. Análise do conteúdo da evidenciação nos relatórios da ad-ministração das empresas participantes dos níveis de governança da BOVESPA. 6. Congres-so USP de Controladoria e Contabilidade. São Paulo, 2006.

HANSEN, D; MOWEN M M. Gestão de custos: contabilidade e controle. São Paulo: Pionei-ra Thomson Learning, 2001.

HENDRIKSEN, E S.; VAN BREDA, M F. Teoria da contabilidade. São Paulo: Atlas, 1999.

IBGC - INSTITUTO BRASILEIRO DE GOVERNANÇA CORPORATIVA. 2008. Código das melhores práticas de governança corporativa. Disponível em: http://www.ibgc.org.br. Acesso em 10 de abril de 2008.

LAKATOS, E M; MARCONI, M A. Fundamentos de metodologia científica. 3. 
ed. São Paulo: Atlas, 1991.

LANZANA, A, P. Relação entre disclosure e governança corporativa das empresas brasi-leiras. Dissertação (Mestrado em Administração) - Curso de Pós-Graduação em Administra-ção, Universidade de São Paulo, São Paulo, 2004.

LOCKAMY III, A. A constraint-based framework for estrategic cost management. Industrial Management + Data Systems. Wembley, 2003 Vol. 103, Issue 8/9, p. 591-599.

MALHOTRA, N. K. Pesquisa de marketing: uma orientação aplicada. 4 ed. Porto Alegre: Bookman, 2006.

MONDEN, Y. Sistemas de redução de custos: custo-alvo e custo-kaizen. Porto Alegre: Bo-okman, 1999.

NAKAGAWA, M. ABC - Custeio baseado em atividades. São Paulo: Atlas, 1994.

. Gestão estratégica de custos. São Paulo: Atlas, 1991.

NOSSA, V. Disclosure ambiental: uma análise do conteúdo dos relatórios ambientais de empresas do setor de papel e celulose em nível internacional. Tese (Doutorado em Controla-doria e Contabilidade) - Departamento de Contabilidade e Atuário da Faculdade de Economi-a, Administração e Contabilidade da Universidade de São Paulo. São Paulo, 2002.

PIACENTINI, N. Evidenciação contábil voluntária: uma análise da prática adotada por companhias abertas brasileiras. Dissertação (Mestrado em Ciências Contábeis), - UNISINOS, São Leopoldo, 2004.

PORTER, M. Vantagem competitiva: criando e sustentando um desempenho superior. 24. ed. Rio de Janeiro: Campus, 1989.

RIGGS, W. E. The Delphi technique: an experimental evaluation. Technological Forecasting and Social Change. Vol. 23, 1983, p. 89-94.

ROBLES JR. A. Custos da qualidade: uma estratégia para a competição global. 1. ed. São Paulo: Atlas, 2003.

ROCHA, W. Contribuição ao estudo de um modelo conceitual de sistema de informação de gestão estratégica. Tese (Doutorado em Ciências Contábeis) Faculdade de Economia, Administração e Contabilidade da Universidade de São Paulo, São Paulo, 1999. 
SAKURAI, M. Gerenciamento integrado de custos. São Paulo: Atlas, 1997.

SHANK, J. K.; GOVINDARAJAN, V. A revolução dos custos: como reinventar e redefinir sua estratégia de custos para vencer em mercados crescentemente competitivos. 6 ed. Rio de Janeiro: Campus, 2000.

SOUZA, B. C; ROCHA, W. Fatores condicionantes da gestão de custos interorganizacionais. 8. Congresso USP de Controladoria e Contabilidade. São Paulo, 2008.

SOUZA, M A; LISBOA, L P; ROCHA, W. Práticas de contabilidade gerencial adotadas por subsidiárias brasileiras de empresas multinacionais. BASE, V.1, n. 1, maio/agosto, 2004.

TINOCO, J. E. P; KRAEMER, M. E. P. Contabilidade e gestão ambiental. São Paulo: A-tlas, 2004. 